\title{
SEGUIMIENTO A PROFESIONALES GRADUADOS DE LA URACCAN, GENERACIÓN 2001-2007 ${ }^{[1]}$
}

\author{
Letisia Castillo ${ }^{[2]}$ \\ Mibsam Aragón ${ }^{[3]}$ \\ Argentina García ${ }^{[4]}$ \\ Alba Luz Dávila ${ }^{[5]}$ \\ Marbel Baltodano ${ }^{[6]}$
}

\section{Resumen}

En evaluación de la excelencia en todo el quehacer de la Universidad de las Regiones Autónomas de la Costa Caribe Nicaragüense (URACCAN), se realizó esta investigación con el objeto de valorar la formación en el nivel de licenciatura y el desempeño profesional de la cohorte generacional 2001-2007.

Se encuestaron a 993 profesionales, distribuidos por cada uno de los Recintos Universitarios así: 290 de Las Minas, 253 de Nueva Guinea, 240 de Bilwi y 210 de Bluefields, de un total de 1132, generación que ha egresado de 19 programas de formación profesional. El 68\% corresponde al sexo femenino; el 24\% pertenece a un pueblo indígena o afrodescendientes de las Regiones Autónomas; el 76\% corresponde a la etnia mestiza y la edad promedio es de 37 años. Concerniente a la ocupabilidad de las personas egresadas, el $93 \%$ se encuentran empleadas y la mayoría son asalariadas en instituciones del sector estatal donde ejercen funciones principalmente administrativas y de docencia. Estos profesionales tienen un alto grado de satisfacción con su preparación y han expresado su agradecimiento a la Universidad.

Palabras claves: Seguimiento a profesionales, características de las personas graduadas, fortalezas y debilidades en las carreras cursadas, pertinencia de la formación.

\section{Summary}

In order to assess excellence in all the work of the University of the Autonomous Regions of the Caribbean Coast of Nicaragua (URACCAN), this research was conducted, with the aim of assessing the training in the level of licentiate and the professional performance of the 2001-2007 generational cohort.

\footnotetext{
${ }^{[1]}$ Investigación libre auspiciada por SAIH Noruega.

[2] Máster en Docencia Universitaria, Secretaria Académica de la URACCAN Las Minas. letycuba2001@yahoo.com

[3] Máster en Ciencias Sociales, Secretaria Académica de URACCAN Nueva Guinea. mibsamaragon@yahoo.com

[4] Máster en Artes, Secretaria Académica de la URACCAN Bilwi. argentina_garcia@yahoo.com

[5] Máster en Pedagogía, Secretaria Académica de la URACCAN Bluefields. albaluzda@yahoo.com

[6] Máster en Evaluación, Directora Académica de la URACCAN. Marbel.Baltodano@yahoo.com
} 
A survey was made with 993 professionals, distributed by each of the campuses: 290 from Las Minas, 253 from Nueva Guinea, 240 from Bilwi and 210 from Bluefields, from a total of 1132 that corresponds to the generation that has graduated from 19 vocational training programs. $68 \%$ were females; $24 \%$ belong to an Indigenous or Afrodescendant people from the Autonomous Regions; $76 \%$ belong to the Mestizo population and the average age is 37 years old. Regarding the employability of these graduates, $93 \%$ are actually employed and most are working with governmental institutions, where they mainly exercise an administrative role and teaching. These professionals have a high level of satisfaction with their preparation and therefore, have expressed their gratitude to the University.

Keyword: Professional Monitoring, characteristics of the graduates, strengths and weaknesses of the careers, relevance of the training.

\section{Introducción}

En la actualidad, la creciente exigencia de calidad por parte de los empleadores respecto al nivel profesional recibida por quienes ofertan sus servicios, obliga a las universidades a elevar la calidad en el proceso de formación y educación que desarrolla.

Desde la sociedad, la eficiencia y eficacia profesional constituye testimonio hacia la excelencia en los programas e instituciones, conjuntamente con la producción científica y tecnológica, y otras evidencias del quehacer académico y social. Por lo tanto, las demandas planteadas a la Educación Superior pueden sintetizarse en un objetivo: Mejorar y asegurar la calidad de la formación para garantizar a la sociedad profesionales idóneos para resolver los problemas de índole social, económicos, políticos y culturales (Jaramillo; Ortiz; Zuluaga; Almonacid \& Acebedo, 2002).

Por tanto, los egresados son la mejor proyección social de la Universidad; su inserción en el mercado laboral, el desempeño profesional específico, las realizaciones y los reconocimientos alcanzados testimonian la calidad de la formación. Por todo ello, el examen minucioso de sus condiciones de trabajo, de sus trayectorias laborales, académicas y sociales, constituyen valiosos indicadores sobre la calidad de las carreras ofrecidas y fuente importante de reflexión para la Universidad (Ibíd.).

La URACCAN, tiene la misión de contribuir al fortalecimiento del proceso de Autonomía de la Costa Caribe nicaragüense, mediante la capacitación y profesionalización de recursos humanos, dotándolos de los conocimientos necesarios para conservar y aprovechar de forma racional y sostenida los Recursos Naturales.Durante quince años de ejercicio académico ha formado nuevos profesionales, que portan la cultura de la Universidad, los valores que inspiran sus procesos académicos y administrativos, y quienes se convierten en la prolongación social, en actores del desarrollo integral de la comunidad y para lo cual aún falta la medición del impacto que efectúan con su 
desempeño en los distintos ámbitos profesionales y sociales, en las cuales despliegan y reflejan la calidad del proceso educativo.Los estudios sobre seguimiento de graduados constituye un aporte en la búsqueda de la calidad en todo el quehacer de la Educación Superior. Para el caso de la Universidad, el seguimiento de graduados ha sido un reto insoslayable, pues éste ha sido una carencia detectada en la mayoría de los procesos de autoevaluación y evaluación externa.Este estudio aporta a las universidades elementos fundamentales para el mejoramiento de sus programas académicos y de la organización para su desarrollo. De modo que no pueden omitirse los procesos de aseguramiento de la calidad de la Educación Superior, sino que deben constituirse en uno de los pilares fundamentales (Fresán, 2004).

Desde esta perspectiva, realizamos un estudio de seguimiento a la comunidad estudiantil graduada en los lugares donde tiene presencia la URACCAN, cohorte generacional 2001-2007, permitiendo iniciar un proceso de seguimiento sistemático por parte de nuestra institución, que permitiría obtener información para indicar las fortalezas y deficiencias para realizar las innovaciones pertinentes a nivel curricular.

\section{II.Revisión de literatura}

La razón de ser de la URACCAN, está en la formación de profesionales y el desarrollo de la investigación científica, su organización sustantiva es lo académico, eje en torno al cual se establecen las políticas, estrategias y coordinación de acciones para cumplir con la Misión y contribuir al fortalecimiento de la Autonomía de la Costa Caribe nicaragüense. Se integra a la sociedad por medio de sus egresados, quienes serán el vehículo mediante el cual el espíritu universitario logre penetrar en ella. Si logra que sus egresados interactúen en sociedad: con espíritu universitario, crítico y humanista, pensamiento autónomo y una ética impregnada del sentido de justicia, equidad, tolerancia y autocrítica, la universidad será útil y provechosa para su sociedad (Parent; Esquivel; Farrand; Masse \& Pérez, 2003).

Los mismos autores determinan que las funciones sociales de la universidad pueden resumirse en lo siguiente:

a. Preparar individuos capaces de dar en la interacción social lo mejor del espíritu universitario: el respeto y el diálogo con sus interlocutores.

b. Ponderar y generar el deseo por la verdad en el saber, para que convertidos en valores, trasciendan el espacio universitario llegando a la sociedad.

c. Promover en la sociedad valores de justicia y equidad, que son los que emanan del sentimiento democrático. 
La UNESCO (1998) establece el "deber ser" de una universidad en el siglo XXI (dinámica-proactiva) al considerar para ello:

1. Un lugar de formación de alta calidad, donde el acceso dependa del mérito intelectual.

2. Una comunidad dedicada a la investigación, creación y difusión del conocimiento.

3. Un lugar donde se promueva el auto-aprendizaje y la responsabilidad social.

4. Un lugar que actualice y perfeccione a sus egresados.

5. Una comunidad que apoye activamente la cooperación con la industria.

6. Un lugar donde se discutan problemas y soluciones locales, regionales, nacionales e internacionales.

7. Un lugar donde el gobierno y demás instituciones públicas encuentren información científica y viable y que también provea la participación en el proceso de la toma de decisiones.

8. Una comunidad comprometida con sus valores tradicionales.

9. Bien ubicada en el contexto mundial y en las características de cada región y de cada país.

Cualquier estudio sobre egresados se inscribe en el contexto de la evaluación de la calidad de los programas y procesos educativos de formación y, por tanto, de la institución que otorga el título (Jaramillo; Ortiz; Zuluaga; Almonacid y Acebedo, 2002).

Una calidad que se manifiesta en las competencias desarrolladas, en los desempeños de profesionalidad y mejoramiento de las condiciones de empleabilidad de los egresados y la productividad de las empresas, así como en la adecuada respuesta a los requerimientos de sujetos de atención diversa: individuos, empresas, sectores y cadenas productivas, comunidades, etc.

Se requiere en definitiva de una formación para la empleabilidad, entendida según la recomendación 195 de la OIT: "competencias y cualificaciones transferibles que refuerzan la capacidad de las personas para aprovechar las oportunidades de educación y formación que se les presenten con miras a encontrar y conservar un trabajo decente, progresar en la empresa o al cambiar de empleo adaptarse a la evolución de la tecnología y de las condiciones del mercado de trabajo" (acápites 3.d).

En este sentido, la calidad de la formación impartida se manifiesta no sólo por la coherencia académica entre teoría y práctica, sino también por la viabilidad del ejercicio profesional que permite demostrar las competencias adquiridas. Por esta razón, también se consulta la opinión de los egresados sobre la calidad de la formación recibida, 
expresada en su satisfacción con el programa cursado, la pertinencia laboral y su importancia para la sociedad (Jaramillo; Ortiz; Zuluaga; Almonacid y Acebedo, 2002).

\section{Materiales y métodos}

La URACCAN se define como una Universidad intercultural, comunitaria y de servicio público, cuya Visión se centra en que es la Universidad intercultural de los pueblos indígenas, afrodescendientes y comunidades étnicas de la Costa Caribe nicaragüense a través del acompañamiento de procesos de autogestión, unidad multiétnica y la formación integral de mujeres y hombres de la Costa Caribe.

Desde inicio de 1995 hasta el año 2007, 1132 hombres y mujeres en su mayoría de escasos recursos económicos y de diferentes pueblos indígenas, afrodescendientes y etnias de la Costa Caribe nicaragüense se han graduado en el nivel de licenciatura o su equivalente en 19 carreras. Lo cual significa un profesional provisto de competencias laborales, bajo la influencia de ciertos valores, creencias, costumbres, actitudes y prácticas, que le transmite nuestro sello institucional y que influyen en su inserción y desempeño en la sociedad.

Enfoque de la investigación: Cuantitativo.

Tipo de investigación: descriptiva, transversal ya que la población de ex estudiantes fue encuestada solamente una vez en un tiempo definido.

\section{Población y muestra}

Se pretendió seleccionar al 100\% de profesionales del período en estudio; sin embargo, de quienes conforman el universo, hay quienes emigraron a otros municipios o están fuera del país, y un pequeño porcentaje no pudo cumplir con el proceso de la encuesta, aparentemente no tenían tiempo o mucho se movilizaban de un lugar a otro. Siendo la muestra analizada de 993 profesionales, específicamente 290 de Las Minas, 253 de Nueva Guinea, 240 de Bilwi y 210 de Bluefields.

\section{Técnicas e instrumentos empleados}

Se desarrolló el estudio siguiendo la modalidad de estudios de seguimiento de egresados, utilizando la encuesta como técnica y el cuestionario.

\section{Etapas}

Comprendió tres etapas: acopio y sistematización de la información requerida, procesamiento de la información con el programa estadístico SPSS; análisis de esta información y emisión de un juicio fundamentado y de recomendaciones para tomar decisiones. 


\section{Resultados y discusión}

\section{Caracterización de las personas graduadas en el nivel de licenciatura, generación 2001 - 2007}

La URACCAN en su trayectoria institucional de Educación Superior hasta el 2007 ha formado y titulado a 1132 profesionales en el nivel de licenciatura en 19 carreras. El 62\% corresponde al sexo femenino, papel de relevancia en la consolidación de estructuras igualitarias de oportunidades entre mujeres y varones en el ámbito de la formación académica.

Es notorio que de esta distribución de la matrícula es mayoritariamente femenina, excepto en algunas carreras, tales como: Ingeniería Agroforestal, Zootecnia y Ciencias de la Educación con mención en Matemática. Lo cual evidencia que todavía hay que seguir realizando acciones destinadas a romper con los estereotipos entre los sexos y las profesiones, es decir a la superación de algunas de las "barreras intangibles" entre tipos de estudios considerados "femeninos" o "masculinos" que sustentan la "segregación sexual de las ocupaciones".

El 24\% del total de personas graduadas pertenece a un pueblo indígena o afrodescendientes de la región, lo que demuestra que la URACCAN crea espacios de equidad en la oportunidad de ingreso, atención con pertinencia cultural y reconocimiento de la diversidad étnica, cultural y de pensamiento en la perspectiva del desarrollo propio.

La población de estudiantes graduados (mujeres y hombres) presenta las siguientes características etáreas: la edad promedio para el total de titulados es de 37 , la edad más representativa está entre 26 a 40, la mínima es de 23 y de 62 años la máxima, esta última no muy representativa. Cabe mencionar que el total de la población se encuentra en edad de trabajar (entre 18 y 65 años).

Las carreras que más profesionales ha formado son: Ingeniería Agroforestal, las Licenciaturas en Administración de Empresas y en Sociología, lo cual se debe a que son los programas académicos más antiguos de la Universidad, es decir son las que se aperturaron con el inicio de la universidad y siguen siendo parte de la oferta académica actual.

En términos de tasas de crecimiento en el número de graduadas y graduados anuales, en las carreras se registran dinámicas diferentes. En todos los años analizados el mayor índice de graduación se generó en las carreras de Ingeniería Agroforestal, 
las Licenciaturas en Administración y en Sociología las que además de graduar a más estudiantes lo han hecho en todos los años analizados.

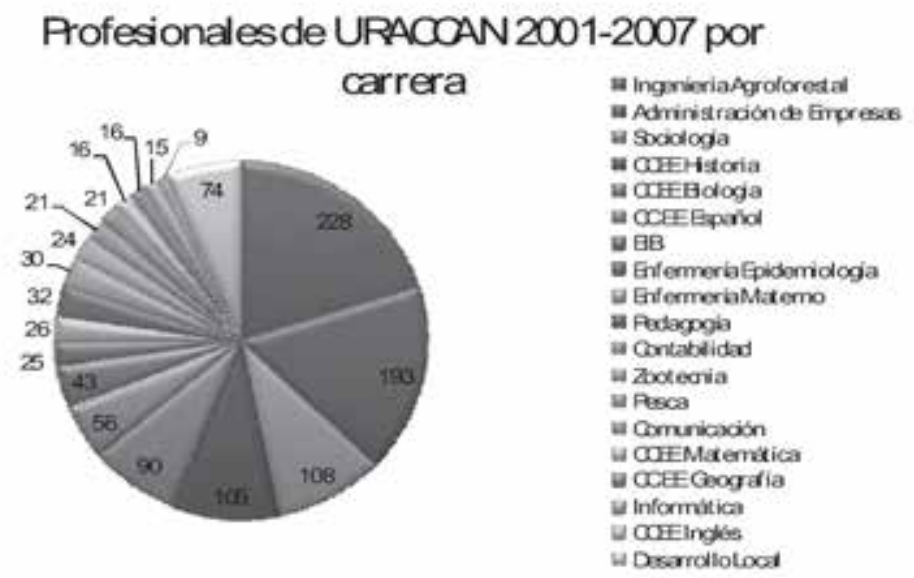

Gráfico No. 1. Profesionales de la URACCAN por carrera, período 2001-2007

Las posibilidades laborales están condicionadas según el grado de aceptación y posicionamiento (hablando en términos de mercadeo), de esa marca; con ella, el egresado no sólo ofrece su capacidad de trabajo, sino todo un testimonio institucional de calidad y de imagen en el mercado laboral.

Al encuestar a las graduadas y los graduados con respecto a su situación laboral obtuvimos los datos siguientes:

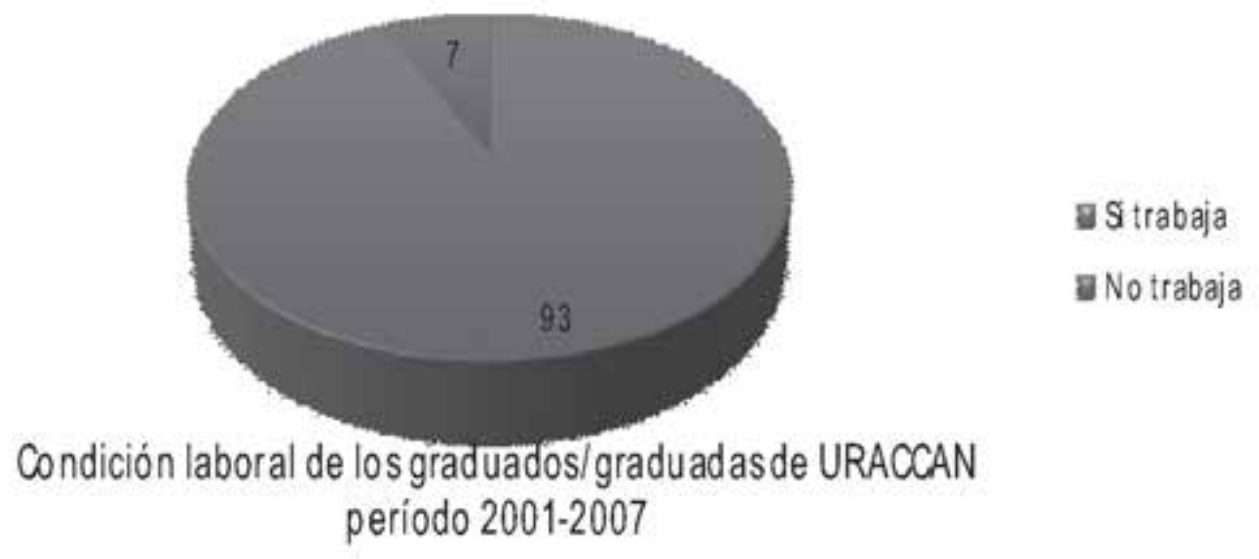

Gráfico No. 2. Condición laboral de los graduados/graduadas en la URACCAN, período 2001-2007 
Lo que significa que la mayoría de los profesionales están empleados. Esto es satisfactorio para la Universidad, ya que cuando ingresan al mercado laboral, llevan consigo una impronta que lo define como persona y como profesional, en mejora de la calidad de vida tanto personal como de la población en general por los aportes que hacen como profesionales.

Es significativo destacar que la mayoría son asalariados (88.06\%), seguidos por quienes ocupan una posición de patrones o empleadores de su propio negocio. En cuanto al tipo de institución en donde trabajan, más de la mitad (63\%) de los graduados y graduadas se encuentran laborando en instituciones del sector estatal, el resto se ubica en organizaciones privadas y otros. Donde la mayoría se encuentran desempeñando funciones docentes y administrativas.

\section{Valoración de la formación recibida en la URACCAN}

Los conocimientos adquiridos por la mayoría de quienes se graduaron son considerados suficientes, el $65 \%$, afirman que se desempeñan con eficiencia en el trabajo que ejercen, los docentes que les impartieron las diversas asignaturas en su mayoría estaban bien preparados y son considerados como excelentes.

“...los docentes de la universidad son excelentes, ya que nos brindaron las pautas para auto prepararnos con bases sólidas”.

Además cada carrera es amplia y facilita la inserción en cualquier campo, en síntesis se considera que desde la universidad se brindaron las herramientas esenciales para el desempeño profesional y hay que seguir actualizándose.

La mayoría de los graduados y graduadas se sienten con satisfacción y expresan un gran agradecimiento por la formación recibida en la la URACCAN.

“... La formación recibida en la Universidad me ha ayudado a integrarme mejor como agente de cambio en la comunidad".

“... Afirmo que he tenido la oportunidad de sentirme realizada en lo profesional y en lo personal”.

“... Mi desempeño laboral ha sido mejor".

“... Estoy en condiciones de demostrar en cualquier parte que tengo una buena formación y al mismo tiempo estoy orgulloso por ser uno de los primeros graduados de URACCAN". 
“... La universidad nos preparó para realizar múltiples actividades y estoy consciente y seguro que no voy a defraudar la formación que recibí".

“... La formación recibida en la universidad permitió que mi desempeño cambiara para bien de la comunidad educativa".

“... Mi sueño ya es realidad”.

“... Gracias a la universidad hoy en día soy lo que soy, tengo mi trabajo y vivo feliz con mi familia”.

“... De no haberme profesionalizado en URACCAN hoy en día estuviese trabajando en la minería artesanal”.

“... Con el tiempo que estuve en URACCAN aprendí que tan importante es crecer profesionalmente sin distinguir raza, color, religión y política”.

“... Las carreras están acorde a nuestra realidad”.

“... El conocimiento adquirido durante mis estudios en la universidad y la experiencia en mi cargo profesional me ha ayudado a salir adelante”.

“... Al competir con otros profesionales que han tenido su formación en otras universidades queda al descubierto que los profesionales de la URACCAN son competentes".

“... Estoy orgullosa de haberme formado en esta universidad ya que enseñan a cultivar valores y respetar nuestros orígenes, también abordamos los temas de género e interculturalidad y esto solamente se aprende en URACCAN".

Estas expresiones demuestran lo importante que es el trabajo que está desempeñando la URACCAN. No obstante, el $20 \%$ expresó que las competencias y los conocimientos adquiridos son medianamente suficientes porque consideran que hizo falta más práctica de campo, laboratorios; además en las ocasiones que se hubo de salir de gira de campo se enseñaba poco, también se percibía poco dominio de la materia, también en algunos momentos faltó interés por parte de la comunidad estudiantil. Es importante clarificar que estamos en un mundo cambiante en tecnología y nuevas leyes laborales, por lo tanto, hay que vivir a la par de todos estos cambios. 


\section{Fortalezas y debilidades de las carreras desde la percepción de quienes se graduaron}

Las fortalezas y debilidades según la opinión de quienes se profesionalizaron en las diferentes carreras ofertadas en el período de estudio se presentan en el siguiente cuadro.

En las distintas especialidades los profesionales expresan la necesidad de fortalecer conocimientos en computación, al considerarlo imprescindible en cualquier campo laboral, esa misma reflexión la hacen respecto al inglés, pues la globalización es exigente y nos debemos involucrar en sus constantes procesos de cambio. Finalmente, este estudio revela que en el caso en las carreras de Administración de Empresas y Ciencias Sociales con mención en Desarrollo Local, demandan para estas disciplinas más profundidad en la parte contable, aduciendo que: el administrador debe ahondar en la parte contable porque una de sus funciones es revisar el trabajo del contador para tomar decisiones y en el caso del desarrollo local, consideran que para administrar proyectos sociales, se les hace indispensable tener conocimientos contables a fin de discernir la factibilidad de estos en términos de costos.

Cuadro No. 1: Fortalezas y debilidades de las carreras según opinión de graduados.

\begin{tabular}{|c|c|c|}
\hline Carrera & $\begin{array}{c}\text { Fortalezas del perfil } \\
\text { profesional para } \\
\text { empleo }\end{array}$ & $\begin{array}{c}\text { Debilidades del perfil } \\
\text { profesional para } \\
\text { empleo }\end{array}$ \\
\hline Ingeniería Agroforestal. & $\begin{array}{l}\text { - Enfoque en desarrollo co- } \\
\text { munitario, administrativo } \\
\text { - M medio ambiente. } \\
\text { - Enfoque jurídico ambiental. } \\
\text { Húmedo). } \\
\text { - Informática. } \\
\text { - Conocimientos de auto } \\
\text { desarrollo rural, conoci- } \\
\text { mientos científicos y tra- } \\
\text { dicionales. }\end{array}$ & $\begin{array}{l}\text { - Poco enfoque agrícola. } \\
\text { - Falta de paquetes de } \\
\text { informática de recursos } \\
\text { naturales. } \\
\text { - Falta de fomento para la } \\
\text { innovación y el empren- } \\
\text { dimiento. } \\
\text { - Poco conocimiento sobre } \\
\text { manejo y aprovechamien- } \\
\text { to de áreas protegidas. }\end{array}$ \\
\hline Ingeniería en Zootecnia. & - El plan de estudio. & $\begin{array}{l}\text { - Falta de temas adminis- } \\
\text { trativos y financieros. } \\
\text { - Pocas prácticas de cam- } \\
\text { po. }\end{array}$ \\
\hline
\end{tabular}




\begin{tabular}{|c|c|c|}
\hline Carrera & $\begin{array}{c}\text { Fortalezas del perfil } \\
\text { profesional para } \\
\text { empleo }\end{array}$ & $\begin{array}{c}\text { Debilidades del perfil } \\
\text { profesional para } \\
\text { empleo }\end{array}$ \\
\hline Licenciatura en Sociología. & $\begin{array}{l}\text { - Perfil social e investiga- } \\
\text { tivo. } \\
\text { - Planificación, monitoreo y } \\
\text { evaluación de procesos. }\end{array}$ & $\begin{array}{l}\text { Falta de temas adminis- } \\
\text { trativos y de gerencia. }\end{array}$ \\
\hline $\begin{array}{l}\text { Ciencias de la Educación con } \\
\text { mención en Biología. }\end{array}$ & $\begin{array}{l}\text { - Conocimientos, habili- } \\
\text { dades y destrezas que } \\
\text { contribuyen a una mejor } \\
\text { práctica docente. } \\
\text { - Los ejes transversales de } \\
\text { la universidad. }\end{array}$ & $\begin{array}{l}\text { - Falta de práctica de labo- } \\
\text { ratorios y bibliografía. } \\
\text { - Falta de Idioma (Inglés) } \\
\text { como asignatura. } \\
\text { - Falta de las herramientas } \\
\text { de Informática. }\end{array}$ \\
\hline $\begin{array}{l}\text { Ciencias de la Educación con } \\
\text { mención en Historia. }\end{array}$ & $\begin{array}{l}\text { - Conocimientos, habili- } \\
\text { dades y destrezas que } \\
\text { contribuyen a una mejor } \\
\text { práctica docente. } \\
\text { - Desempeño profesional } \\
\text { en los diferentes niveles } \\
\text { deeducación. }\end{array}$ & $\begin{array}{l}\text { - Desarrollo de la ética } \\
\text { como un valor humano. } \\
\text { - Falta de las herramientas } \\
\text { de Informática. }\end{array}$ \\
\hline $\begin{array}{l}\text { Licenciatura en Ciencias } \\
\text { Sociales con mención en } \\
\text { Desarrollo Local. }\end{array}$ & $\begin{array}{l}\text { - Enfoque social y de desa- } \\
\text { rrollo. } \\
\text { - Habilidades en el uso de } \\
\text { las tecnologías de la infor- } \\
\text { mación y de la comuni- } \\
\text { cación. } \\
\text { - Formulación, evaluación } \\
\text { y administración de pro- } \\
\text { yectos. }\end{array}$ & $\begin{array}{l}\text { - Poca profundidad en los } \\
\text { temas estadísticos. }\end{array}$ \\
\hline Administración de Empresas & $\begin{array}{l}\text { - El perfil profesional con } \\
\text { todas sus menciones. }\end{array}$ & $\begin{array}{l}\text { - Falta de computación. } \\
\text { - Falta de prácticas. } \\
\text { - } \text { Falta de conocimientos } \\
\text { - Falta lenguas indígenas. } \\
\text { de organización de com- } \\
\text { pras, suministro y manejo } \\
\text { de bodega, relaciones } \\
\text { humanas, higiene y } \\
\text { seguridad ocupacional- } \\
\text { empresarial, diseño y } \\
\text { elaboración de pequeños } \\
\text { negocios. }\end{array}$ \\
\hline
\end{tabular}




\begin{tabular}{|c|c|c|}
\hline Carrera & $\begin{array}{c}\text { Fortalezas del perfil } \\
\text { profesional para } \\
\text { empleo }\end{array}$ & $\begin{array}{c}\text { Debilidades del perfil } \\
\text { profesional para } \\
\text { empleo }\end{array}$ \\
\hline $\begin{array}{l}\text { Educación Intercultural } \\
\text { Bilingüe }\end{array}$ & $\begin{array}{l}\text { - Competencias educativas. } \\
\text { - El idioma mayangna, su } \\
\text { gramática. } \\
\text { - Amplio conocimiento de } \\
\text { la cultura de los pueblos } \\
\text { indígenas. }\end{array}$ & $\begin{array}{l}\text { - Pocos conocimientos del } \\
\text { idioma español. }\end{array}$ \\
\hline
\end{tabular}

Es notorio señalar que las carreras que no se mencionan en el cuadro anterior, se debe a que las graduadas y graduados hacen referencias generales y tienen una valoración positiva.

Además, manifestaron que ahora la URACCAN tiene mejores condiciones, por lo tanto, quienes actualmente están en proceso de formación, tienen mayores oportunidades de recibir una educación integral que facilite su inserción en puestos de trabajo acorde a su profesión.

El interés por continuar formándose está latente en el 9o\% de informantes, esto nos compromete a ampliar nuestra oferta académica postgraduada para estos profesionales que desean continuar enriqueciendo sus conocimientos en distintas especialidades.

La modalidad de preferencia para realizar estudios de postgrado es por encuentro, esto se debe a que las responsabilidades laborales y familiares limitan sus intereses a continuar estudios en otras modalidades.

Las personas graduadas desean realizar estudios de postgrado con el objetivo de especializarse, para esto le proponen a la Universidad:

- Desarrollo Rural.

- Formulación, Monitoreo y Evaluación de Proyectos.

- Metodología de la Investigación.

- Pedagogía.

- Inglés.
-Administración de Recursos Humanos.

- Dirección de Empresas y Mercadeo.

- Administración Pública y Financiera.

- Administración y Contabilidad.

- Gestión de Riesgo y Cambio climático.

- Salud Pública. 
- Educación Intercultural Bilingüe.

- Ciencias Ambientales.

- Manejo de Recursos Naturales.

- Forestería Comunitaria.

- Administración Escolar.

- Ciencias Sociales.

- Antropología.

- Lingüística.
- Economía Ambiental.

- Manejo de Ganado.

- Administración de Negocios.

- Epidemiología.

- Salud Comunitaria.

- Salud Mental.

- Salud Sexual Reproductiva.

- Administración en Salud o Gerencia en Salud.

\section{Conclusiones}

- La URACCAN en su trayectoria institucional de Educación Superior hasta el 2007 ha formado y titulado a 1,132 profesionales en el nivel de licenciatura en 19 programas de formación con un total de 22 carreras.

- El $62 \%$ son del sexo femenino, aunque la distribución por género varía entre carreras, así por ejemplo en las carreras de Ingenierías, Ciencias de la Educación con mención en Matemática prevalece el sexo masculino.

- El 24\% pertenece a un pueblo indígena o afrodescendiente de la región, lo que demuestra que la URACCAN crea espacios para el acceso con mejores condiciones de equidad, atención con pertinencia cultural y reconocimiento de la diversidad étnica, cultural y de pensamiento en la perspectiva del desarrollo propio.

- La edad promedio para el total de titulados es de 37 años, la edad más representativa está entre 26 a 40 años y la edad la mínima 23 años y 62 años la máxima, esta última no muy representativa.

- Las carreras que más graduadas y graduados tienen son las carreras de Ingeniería Agroforestal, las Licenciatura en Administración de Empresas y en Sociología, esto se debe a que son las carreras más antiguas, es decir son las que se aperturaron con el inicio de la Universidad.

- $\quad$ El 93\% de los profesionales se encuentran empleados. Esto es muy satisfactorio, ya que cuando un graduado/a ingresa al mercado laboral, lleva consigo una impronta que lo define en una proyección de mejorar la calidad de vida tanto personal como de la población en general por los aportes que hacen como profesionales. 
- La mayor parte de los profesionalizados de la URACCAN son asalariados (88.06\%), seguidos por quienes ocupan una posición de patrones o empleadores de su propio negocio.

- El 63\% de la generación 2001-2007 se encuentran laborando en instituciones del sector estatal, el resto se ubica en organizaciones privadas y otros.

- La mayoría se encuentra desempeñando funciones docentes y administrativas.

- Los conocimientos adquiridos de los profesionalizados en su mayoría son considerados suficientes, pues en este sentido el $65 \%$, afirma que gracias a ello han podido desempeñarse con eficiencia en el trabajo que ejercen, los docentes que les impartieron las diversas asignaturas en su mayoría estaban bien preparados y son considerados como excelentes

- El interés por continuar formándose está latente en el 9o\% de las y los informantes, esto nos compromete a a ampliar nuestra oferta académica de postgrado para estos profesionales que desean continuar enriqueciendo sus conocimientos en distintas especialidades.

\section{Lista de referencia}

Fresán, M., (1998). Los estudios de egresados. Una estrategia para el autoconocimiento y la mejora de las Instituciones de Educación Superior. En Esquema básico para los estudios de egresados en educación superior. México: Asociación Nacional de Universidades e Instituciones de Educación Superior.

Jaramillo, A; Ortiz, J; Zuluaga, E; Almonacid, P y Acebedo, S. (2002). Impacto social de los programas de pregrado. UNIVERSIDAD EAFIT. Obtenido el 21 de Diciembre del 2006 en www.eafit.edu.co/planeacion/sistemacalidad/procesoAcredita... sentirdelosEgresados.pd

Parent, J.M; Esquivel, N.H; Farrand, J; Massé, C.E; Pérez, E.I (1996). ¿Tiene función social la Universidad? Acervo Bibliohemerográfico de la Universidad Autónoma del Estado de México. Toluca, México. Obtenido el 21 de Diciembre del 2006 en http://www.uaemex.mx/ceu/folletos/funcion.html.

UNESCO (1998). Conferencia Mundial sobre Educación Superior. Informe Final, París. convenio de la oit 